Article

\title{
Understanding the Determinants and Future Challenges of Cloud Computing Adoption for High Performance Computing
}

\author{
Theo Lynn *,t, (1), Grace Fox ${ }^{t, \ddagger}$, Anna Gourinovitch ${ }^{t, \ddagger}$ and Pierangelo Rosati ${ }^{t, \ddagger(1)}$ \\ Irish Institute of Digital Business, Dublin City University; Collins Avenue, D09 Dublin, Ireland; \\ grace.fox@dcu.ie (G.F.); anna.gourinovitch2@mail.dcu.ie (A.G.); pierangelo.rosati@dcu.ie (P.R.) \\ * Correspondence: theo.lynn@dcu.ie \\ + All the authors contributed equally to this work. \\ $\ddagger$ This paper is an extension of a paper originally presented at the 51st Hawaii International Conference on \\ System Sciences (HICSS-51). A second supplemental study has been added.
}

Received: 14 July 2020; Accepted: 5 August 2020; Published: 11 August 2020

check for updates

\begin{abstract}
High performance computing (HPC) is widely recognized as a key enabling technology for advancing scientific progress, industrial competitiveness, national and regional security, and the quality of human life. Notwithstanding this contribution, the large upfront investment and technical expertise required has limited the adoption of HPC to large organizations, government bodies, and third level institutions. Recent advances in cloud computing and telecommunications have the potential to overcome the historical issues associated with HPC through increased flexibility and efficiency, and reduced capital and operational expenditure. This study seeks to advance the literature on technology adoption and assimilation in the under-examined HPC context through a mixed methods approach. Firstly, the determinants of cloud computing adoption for HPC are examined through a survey of $121 \mathrm{HPC}$ decision makers worldwide. Secondly, a modified Delphi method was conducted with 13 experts to identify and prioritize critical issues in the adoption of cloud computing for HPC. Results from the quantitative phase suggest that only organizational and human factors significantly influence cloud computing adoption decisions for HPC. While security was not identified as a significant influencer in adoption decisions, qualitative research findings suggest that data privacy and security issues are an immediate and long-term concern.
\end{abstract}

Keywords: cloud computing; high performance computing; HPC; technology adoption models; $\mathrm{HPC}$ in the cloud

\section{Introduction}

Cloud computing is one of the major emergent paradigms in information systems research and practice. Attracted by the promise of information technology (IT) efficiencies and increased business agility, enterprises are incorporating cloud computing in their IT strategies [1]. Despite the extensive literature on the benefits of cloud computing, our understanding of cloud computing adoption decisions is marred by inconsistencies on the influence of a myriad of organizational, technological, environmental, and human factors [2-6], which vary by situational context [7-9]. Thus, in highly complex and under researched contexts such as high performance computing (HPC), there is a need for research that elucidates the role of the various organizational, technological, environmental, and human factors.

Advances in the design of higher performance processors, functional accelerators, interconnects, and associated software have resulted in increasingly powerful computers often referred to as supercomputing or HPC [10]. HPC can be defined as the coordinated use of massive parallel 
architectures for the solution of a single problem and are characterized by the scale of compute power required to process a job quickly [11]. HPC-oriented problems are typically computationally and data intensive simulation and analytics problems [12]. Such advanced computing is costly in terms of upfront capital investment and direct and indirect operational expenditure as HPC requires significant energy and expertise to operate [10]. Due to the cost of HPC, it is unsurprising that HPC is commonly used in automotive and aerospace product development, oil and gas exploration, genomics and drug discovery, weather prediction and climate modeling, 3D image rendering, and complex financial modeling [12]. Thus, access to HPC infrastructure has typically been limited to large mature organizations, government research centers or agencies, and universities [12]. HPC represents a small but high value segment of the ICT market [12,13]. Indeed, a 2015 IDC report for the European Commission highlights the importance of HPC: "The use of high performance computing (HPC) has contributed significantly and increasingly to scientific progress, industrial competitiveness, national and regional security, and the quality of human life. HPC is important for national and regional economies-and for global ICT collaborations in which Europe participates-because HPC, also called supercomputing, has been firmly linked to accelerating innovation" [12].

Geist and Reed [10] note that large-scale commercial cloud computing infrastructures share common scales with large-scale HPC systems with both services driven by cost, reliability, and energy efficiency imperatives. However, they also note important differences. For HPC, performance is key [10], but the emphasis in cloud computing is on scalability, in this case horizontal scaling through the addition of more machines, in contrast to vertical scaling in HPC. Furthermore, recent research has highlighted the potential for cloud computing to overcome many of the issues associated with high performance computing by increasing flexibility and efficiency, and reducing costs [14-16]. HPC infrastructure has traditionally been unavailable to many organizations due to its high cost and the specialized technical knowledge required to configure and maintain such infrastructure [17]. In line with Beck and Toenker [18], we posit that HPC in the cloud allows organizations, particularly small-tomedium enterprises (SMEs), to access HPC infrastructure on a more cost-effective basis and, as a result, better compete by overcoming internal constraints to generate new capabilities, enter new markets, adopt new resources, and develop new products. Similarly, the HPC4AI project posits that federated clouds can support regional and national academic and industrial research through on-demand provisioning of artificial intelligence (AI) and Big Data analytics (BDA) services through collaboration between institutions with complementary resources [16]. Consequently, the use of the cloud for HPC may enable an acceleration of innovation resulting in a positive impact for industry and society as a whole.

Despite the potential benefits, compared to the wider information and communication technology (ICT) market, public cloud computing makes up a relatively small proportion of overall revenues for the HPC market but is beginning to show evidence of strong growth [12,13]. It is thus important to understand the reasons behind organizations' decisions to adopt or not to adopt cloud computing for HPC workloads. Research on HPC in the information systems (IS) literature, and specifically HPC in the cloud, is limited [18,19]. Indeed, the extant research is largely technical in nature and focused on evaluating the potential of different cloud platforms and determining which HPC applications the cloud represents a viable solution for [14,20]. While these studies have enhanced our technical understanding of the potential of cloud computing in the HPC context, there is a dearth of research which explores the factors involved in influencing initial decisions to adopt cloud computing for HPC. This gap in our knowledge is important as developing an understanding of the factors influencing initial decisions to adopt a new technology is paramount to the success of new technologies [21]. With this in mind, the paper explores the following research questions:

RQ1. What are the determinants of cloud computing adoption for HPC? 
$R Q 2$. What are the critical issues that are currently impacting and are likely to impact HPC in the cloud in the near future (1-5 years) and in the long term (5+ years)?

This study seeks to advance the literature on technology adoption and assimilation in the under-examined HPC context through a mixed methods approach. Firstly, the determinants of cloud computing adoption for HPC are examined with a survey of 121 HPC decision makers worldwide [22]. Secondly, a modified Delphi method was conducted with 13 experts to identify and prioritize critical issues in the adoption of cloud computing for HPC. The remainder of this article is organized as follows. In the next section, we discuss the related literature in the cloud computing context. Two pertinent theories are integrated to develop the research model in Section 3. The methodologies and findings for the quantitative and qualitative phases of the study are presented in Sections 4 and 5 , respectively. These are discussed in Section 6. The paper concludes with summary of the study's contribution, limitations and opportunities for future research.

\section{Literature Review}

This paper seeks to examine cloud computing adoption for HPC by leveraging the technology adoption literature in the field of IS.

\subsection{Technology Adoption in Information Systems}

In the 1960s, research in innovation adoption began with Rogers seeking to understand what influenced farmers' decisions to adopt agricultural innovations, with innovations described as an idea, practice, or object that is perceived as new to an individual or organization [23]. Early work in this area focused either on the characteristics of the individual adopting the innovation or the characteristics of the innovation [23]. Since the 1980s, researchers have focused on understanding the factors driving adoption of different technologies, leading to the development of a well-established literature stream and number of theories. These theories can be discussed under two categories: (i) adopter-centered and (ii) innovation or organization centered. The prevailing theories are outlined in Table 1.

The majority of models in the first category are based on the theory of reasoned action (TRA) [24], which posits that individuals' behaviors are formed based on their salient beliefs and attitude toward the behavior. While TRA does not prescribe what these salient beliefs are, it has been leveraged as the underlying foundation of several later models beginning with the technology acceptance model (TAM). TAM lists perceived usefulness and perceived ease of use as the salient beliefs which shape individuals' acceptance and usage of new technologies [25,26]. TAM has been leveraged to examine technology adoption in various contexts and adapted to produce various new models. Venkatesh et al. [21] re-examined the popular technology models to create the Unified Theory of Technology Acceptance and Usage (UTAUT). UTAUT proposes that the likelihood an individual will accept a new technology is based on their perception of the performance expectancy (similar to perceived usefulness), effort expectancy (similar to perceived ease of use), social influence and facilitating conditions to adopt. The first theory in the second category, is Diffusion of Innovation (DOI) theory, which holds that the technology adoption decision is influenced by innovation characteristics: (i) relative advantage, (ii) compatibility, (iii) complexity, (iv) observability, and (v) trialability [23]. Similar to DOI, the TOE Framework proposed by Tornatzky and Fleischer [27] suggests that IT adoption is influenced by three contexts-(i) technological, (ii) organizational, and (iii) environmental. These contexts are consistent with DOI theory in that the technological context incorporates the innovation characteristics. TOE theory also includes organizational factors, such as firm size, technology readiness, employee competence, and top management support [6-9,28,29]. In congruence with DOI and TOE, the HOT-fit model, proposed by Yusof et al. [30], asserts that organizational and technological factors are determinants of successful IS adoption. The HOT-fit model also introduces human factors, claiming that user attitude and competence also have a positive impact on technology adoption [30]. Theories from both categories have been leveraged to study adoption across a wide 
range of contexts with several adaptations and combinations used. However, while the predictive power of adopter-centered theories has been established and human factors are relevant, we argue that the complex nature of HPC lends itself to a broader approach that considers organizational and technological factors.

Table 1. Technology adoption theories.

\begin{tabular}{|c|c|c|}
\hline Model & Author(s) & Dimensions/Factors Included \\
\hline \multicolumn{3}{|c|}{ Theories based on the individual } \\
\hline $\begin{array}{l}\text { Theory of Reasoned action } \\
\text { (TRA) }\end{array}$ & Fishbein and Azjen (1975) & $\begin{array}{l}\text { Individuals' beliefs } \\
\text { Attitude toward behavior (ATT) } \\
\text { Subjective norm (SN) } \\
\text { Behavioral intention }\end{array}$ \\
\hline $\begin{array}{l}\text { Technology acceptance model } \\
\text { (TAM) }\end{array}$ & Davis et al. (1989) & $\begin{array}{l}\text { Perceived usefulness (PU) } \\
\text { Perceived ease of use (PEOU) }\end{array}$ \\
\hline $\begin{array}{l}\text { Theory of Planned behavior } \\
\text { (TPB) }\end{array}$ & Ajzen (1991) & $\begin{array}{l}\text { Attitude toward behavior adapted from TRA } \\
\text { Subjective norm adapted from TRA (SN) } \\
\text { Perceived behavioral control (PBC) }\end{array}$ \\
\hline UTAUT & Venkatesh et al., (2003) & $\begin{array}{l}\text { Performance Expectancy (PE) } \\
\text { Effort Expectancy (EE) } \\
\text { Social Influence (SI) } \\
\text { Facilitating Conditions (FC) } \\
\text { Moderators: gender, age, experience, } \\
\text { Voluntariness }\end{array}$ \\
\hline \multicolumn{3}{|c|}{ Theories based on the innovation and wider environment } \\
\hline $\begin{array}{l}\text { Diffusion of Innovations } \\
\text { (DOI) }\end{array}$ & Rogers $(1995 ; 2003)$ & $\begin{array}{l}\text { Relative advantage } \\
\text { Ease of use } \\
\text { Image } \\
\text { Visibility } \\
\text { Compatibility } \\
\text { Results demonstrability } \\
\text { Voluntariness of Use }\end{array}$ \\
\hline $\begin{array}{l}\text { Technology-Organization-Environment } \\
\text { (TOE) }\end{array}$ & Tornatzky and Fleischer (1990) & $\begin{array}{l}\text { Technology: innovation characteristics, availability } \\
\text { Organization: size, management support, } \\
\text { organizational resources } \\
\text { External Environment: firm size, external pressure, } \\
\text { industry, regulation, financial }\end{array}$ \\
\hline $\begin{array}{l}\text { Human-Organization-Technology Fit } \\
\text { (HOT-fit) }\end{array}$ & Yusof et al. (2008) & $\begin{array}{l}\text { Human: user satisfaction } \\
\text { Organization: structure, environment } \\
\text { Technology: quality driven factors }\end{array}$ \\
\hline
\end{tabular}

\subsection{Technology Adoption Research in Cloud Computing}

As our review failed to identify any studies which have previously investigated the factors influencing decisions to adopt cloud computing for HPC applications, it was important to review what theories have been utilized in the broader cloud computing context. A recent review of the literature on cloud computing adoption found that many studies fail to utilize the prevailing technology adoption theories [31]. Furthermore, those studies that do adopt a guiding framework lack a unified approach with studies adapting and combining elements of DOI, TOE, and HOT-fit theories. Among these theories, the influential factors in cloud computing can be categorized into four groups: (i) human factors such as personal innovativeness, perceived technical competence [9,30]; (ii) organizational factors including adequacy of resources, top management support, perceived indirect benefits, and relative advantage [7,9,32]; (iii) technological factors such as perceptions of the innovation's complexity, compatibility, and reliability and security [3,5,33]; and (iv) environmental factors such as competitive pressure, government policy, and partner support $[2,7,9,29]$. The existing literature leveraging these theories to understand cloud computing adoption is outlined in Table 2. 
Table 2. Cloud computing adoption literature.

\begin{tabular}{|c|c|c|c|c|c|c|}
\hline Study & Context & Theories & Human Factors & Technology Factors & Organizational Factors & Environmental Factors \\
\hline Low et al. (2011) & $\begin{array}{l}\text { Adoption of Cloud Computing by firms in Taiwan } \\
\text { (111 survey responses) }\end{array}$ & TOE & N/A & $\begin{array}{l}\text { Relative advantage (S) } \\
\text { Complexity (N.S) } \\
\text { Compatibility (N.S) }\end{array}$ & $\begin{array}{l}\text { Size }(\mathrm{S}) \\
\text { Top management support (S) } \\
\text { IT readiness (N.S) }\end{array}$ & $\begin{array}{l}\text { Supplier Support (S) } \\
\text { Competitive Pressure (S) }\end{array}$ \\
\hline Alshamaila et al. (2013) & $\begin{array}{l}\text { Adoption of Cloud Computing by SMEs in England } \\
\text { (15 interviews with SMEs) }\end{array}$ & TOE & $\mathrm{N} / \mathrm{A}$ & $\begin{array}{l}\text { Relative advantage (S) } \\
\text { Uncertainty (S) } \\
\text { Complexity (S) } \\
\text { Trialability (S) }\end{array}$ & $\begin{array}{l}\text { Size (S) } \\
\text { Top management support (S) } \\
\text { Innovativeness (S) } \\
\text { IT Support (S) }\end{array}$ & $\begin{array}{l}\text { Scope (S) } \\
\text { Supplier Support (S) } \\
\text { Competitive Pressure (N.S) } \\
\text { Industry (S) }\end{array}$ \\
\hline Lin and Chen (2012) & $\begin{array}{l}\text { Cloud Computing Adoption in Taiwan } \\
\text { (19 interviews) }\end{array}$ & DOI & N/A & $\begin{array}{l}\text { Relative advantage (S) } \\
\text { Complexity (S) } \\
\text { Compatibility (S) }\end{array}$ & $\mathrm{N} / \mathrm{A}$ & N/A \\
\hline Gupta et al. (2013) & $\begin{array}{l}\text { Cloud computing adoption among SMEs } \\
\text { (211 survey responses) }\end{array}$ & $\mathrm{N} / \mathrm{A}$ & Ease of Use (S) & $\begin{array}{l}\text { Reliability (S) } \\
\text { Perceived Security (S) }\end{array}$ & Cost Saving (S) & $\mathrm{N} / \mathrm{A}$ \\
\hline Hsu et al. (2014) & $\begin{array}{l}\text { Cloud computing adoption among firms in Taiwan } \\
\text { (200 survey responses) }\end{array}$ & TOE & $\mathrm{N} / \mathrm{A}$ & $\begin{array}{l}\text { Perceived Benefits (S) } \\
\text { Business Concerns (S-) }\end{array}$ & $\begin{array}{l}\text { IT Capability (S) } \\
\text { Size (N.S) }\end{array}$ & External Pressure (N.S) \\
\hline Lian et al. (2014) & $\begin{array}{l}\text { Cloud computing adoption in Taiwanese hospitals } \\
\text { (60 survey responses) }\end{array}$ & $\begin{array}{l}\text { TOE } \\
\text { HOT-FIT }\end{array}$ & $\begin{array}{l}\text { Innovativeness (9) } \\
\text { IT Competence (2) }\end{array}$ & $\begin{array}{l}\text { Complexity (5) } \\
\text { Perceived Security (1) } \\
\text { Costs (3) } \\
\text { Compatibility (8) }\end{array}$ & $\begin{array}{l}\text { Relative advantage (11) } \\
\text { Top management support (4) } \\
\text { Adequate Resources (6) } \\
\text { Benefits (12) }\end{array}$ & $\begin{array}{l}\text { Government policy }(7) \\
\text { Competitive Pressure (10) }\end{array}$ \\
\hline Oliveria et al. (2014) & $\begin{array}{l}\text { Cloud computing adoption among Spanish firms } \\
\text { ( } 369 \text { survey responses) }\end{array}$ & $\begin{array}{l}\text { DOI } \\
\text { TOE }\end{array}$ & N/A & $\begin{array}{l}\text { Relative advantage (S) } \\
\text { Complexity (S) } \\
\text { Compatibility (N.S) } \\
\text { Costs (S) } \\
\text { Security (N.S) } \\
\text { Technology Readiness (S) }\end{array}$ & $\begin{array}{l}\text { Size (S) } \\
\text { Top management support (S) }\end{array}$ & $\begin{array}{l}\text { Government policy (N.S) } \\
\text { Competitive Pressure (N.S) }\end{array}$ \\
\hline Wu et al. (2013) & $\begin{array}{l}\text { Adoption of Cloud in Manufacturing and Retail } \\
\text { firms in the US ( } 289 \text { Survey responses) }\end{array}$ & DOI & $\mathrm{N} / \mathrm{A}$ & $\begin{array}{l}\text { Complexity (S) } \\
\text { Compatibility (S) }\end{array}$ & N/A & N/A \\
\hline
\end{tabular}


As highlighted above, there are a number of combinations of these theories, and conflicting categorization of variables as human, organizational, or technical factors. However, several observations can be made. Firstly, there is no dominant model for exploring technology adoption, but there are many similarities among the theories operationalized. Furthermore, the trend of combining numerous theories is evident in this context. This approach is appropriate due to the complementarity of many of the popular technology adoption theories. For instance, DOI, TOE, and HOT-fit theories complement each other, to provide a comprehensive understanding of the key determinants of technology adoption $[3,7,9]$. Secondly, in terms of the human factors and HOT-fit, Lian et al. [9] found support for the influence of innovativeness and IT competence on cloud computing adoption by hospitals in Taiwan. It is thus important to explore the role of human factors in the HPC context. Thirdly, in relation to the organizational factors listed across TOE and HOT-fit models, perceived indirect benefits [8], top management support $[1,5,6]$, and the firm's IT capability all influenced cloud computing adoption [5,8]. Fourthly, a number of innovation characteristics from DOI and the technological factors from HOT-fit and TOE have received support. This includes the role of complexity and compatibility from DOI which was found to influence cloud computing adoption in Taiwan [32] and security [9]. Lastly, prior research offers mixed support for the importance of environmental factors from TOE in the cloud computing context with competitive pressure $[5,7,8]$, regulatory support [7], and partner pressure [6] all found to be insignificant in the cloud context. In this study, we focus on combining two theories, DOI and HOT-fit, for two key reasons. Firstly, the mixed support for the importance of environmental factors and the role of government are not conducive to this study's focus as the HPC market is spread across countries and industries. Second, DOI and HOT-fit include the majority of the TOE elements and are commonly used to explain technology adoption and provide a more holistic understanding of cloud computing adoption $[8,9,34]$.

\section{Research Model and Hypotheses}

DOI theory asserts that the salient innovation characteristics will vary across contexts [35]. Thus, it is imperative to consider the research context when deciding on the appropriate technology adoption factors [34]. Thus, we draw on DOI and HOT-fit to develop the framework proposed in Figure 1.

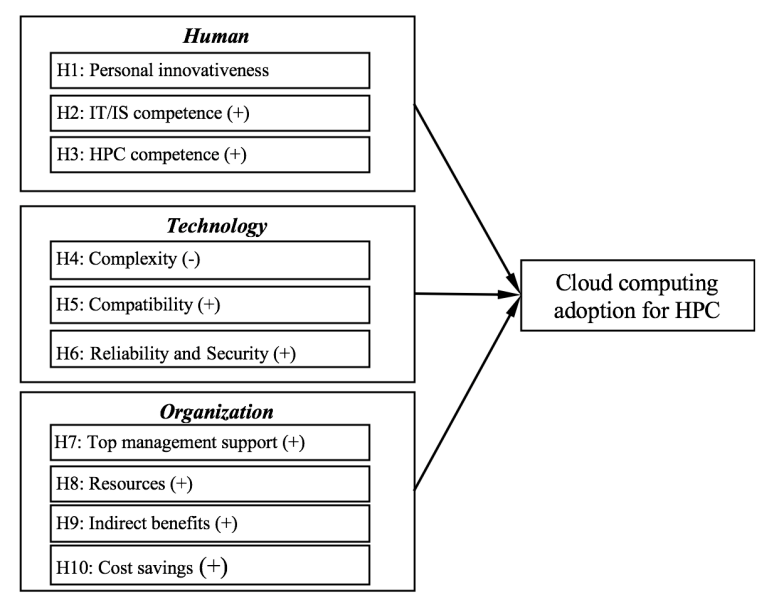

Figure 1. Proposed framework.

\subsection{Human Factors}

Personal innovativeness denotes the openness of an individual to new technology. Studies show that an individual's perceived innovativeness can influence how they respond to new technologies $[9,36]$. Thus, personal innovativeness may predict whether a person intends to adopt an innovation earlier than others [5,36]. Given the lag in adoption of cloud computing in the HPC context, we argue that innovative decision makers are more likely to adopt. Hence, we posit: 
Hypothesis 1 (H1). Personal innovativeness is positively related to the adoption of cloud computing for HPC.

In order to enhance technological readiness, organizations are required to have specialized human resources (e.g., competent HPC staff and/or IT staff) who have the knowledge and skills to implement cloud computing for HPC. Thus, employees' technological competencies may influence cloud computing adoption for HPC workloads. Studies show that IT expertise is essential for organizations that intend to adopt cloud computing $[5,9,29]$. Whilst this expertise may vary depending on the type of cloud computing service, we posit that technical competence is relevant for HPC, as organizations using HPC often use proprietary, tightly configured, or specialist software requiring specialist expertise. Thus, we propose:

Hypothesis 2 (H2). IT/IS competence is positively related to the adoption of cloud computing for HPC.

Hypothesis 3 (H3). HPC competence is positively related to the adoption of cloud computing for HPC.

\subsection{Technological Factors}

Complexity represents perceived difficulty in the usage of an innovation [23]. Organizations tend to adopt new technologies that are easy to use, as complex technologies can result in decreased adoption [29]. Therefore, we posit:

Hypothesis 4 (H4). Complexity is negatively related to the adoption of cloud computing for HPC.

Compatibility refers to "the degree to which an innovation is perceived as consistent with the existing values, past experiences, and needs of potential adopters" [6]. Organizations are less likely to adopt cloud computing if it is not compatible with these values, as adoption may require major adjustments in organizational processes and considerable learning [6,37]. Compatibility has been found to influence cloud computing adoption [5]. It encompasses a wide range of expectations including performance and cloud compatibility with extant practices in an organization and HPC. Thus, we propose:

Hypothesis $\mathbf{5}$ (H5). Compatibility is positively related to the adoption of cloud computing for HPC.

In the context of HPC in the cloud, industry reports suggest concerns within the HPC community that cloud computing may not be a reliable medium to process HPC workloads and that cloud communication speeds may not be sufficient to handle the data movement necessary for such workloads $[12,38,39]$. Security concerns are consistently reported as a major barrier to cloud computing adoption [12]. Security is perceived to directly relate to the reliability of a cloud computing system and is positively associated with the cloud computing adoption decision with higher perceptions of security increasing adoption intentions [14]. Thus, we hypothesize:

Hypothesis 6 (H6). Perceived reliability and security are positively related to the adoption of cloud computing for HPC.

\subsection{Organizational Factors}

The adoption of cloud computing requires the integration of resources and a supportive environment [40]. Top management involvement in the cloud computing adoption decision and implementation process is essential as it guarantees that sufficient resources will be allocated to support implementation [5] and the value of adopting will be communicated throughout the organization [6]. Thus, we propose: 
Hypothesis 7 (H7). Top management support is positively related to the adoption of cloud computing for HPC.

Adequate resources refer to the resources needed for the adoption of cloud computing. Previous studies show that organizations with the necessary resources are more likely to adopt cloud computing [41]. Cloud computing adoption for HPC is a large project that requires top management commitment, ample time, money, competent human resources, and technological competencies $[9,42]$. Thus:

Hypothesis 8 (H8). Adequate resources are positively related to the adoption of cloud computing for HPC.

Extant literature suggests that cloud computing provides organizations with direct and indirect benefits. For instance, cloud computing enables organizations to gain access to hardware, software, or other ICT infrastructure not available in their own data centers [8]. Such advantages are termed direct benefits. In addition to these direct benefits, organizations are also motivated by the indirect benefits, such as improving the organizational image, competitive advantage, or relationships with customers or business partners [43]. We posit:

Hypothesis 9 (H9). Indirect benefits are positively related to the adoption of cloud computing for HPC.

Cloud computing adoption allows organizations to reduce upfront capital expenditure and operational costs, thereby enabling them to gain a cost reduction advantage [41,44]. Studies show that cost reduction is positively associated with organizations' perceptions of the ease of use and convenience of adopting cloud computing, thus increasing adoption intention [33]. HPC infrastructure has extremely high operating costs compared to more general IT [17]. Thus, we posit:

Hypothesis 10 (H10). Cost reduction is positively related to the adoption of cloud computing for HPC.

\section{Factors Influencing Cloud Adoption for HPC}

\subsection{Methodology}

A questionnaire was designed to test the proposed framework presented above. The first stage of questionnaire design involved sourcing validated items to represent all of the variables in the framework. All items were sourced from the technology adoption literature and adapted to fit the context of HPC. Perceived innovativeness (four items), HPC competence (six items), IT/IS competence (five items), complexity (five items), and adequate resources (four items) were adapted from [9]. The six items used to measure indirect benefits were adapted from $[9,43]$. Top management support (three items) and compatibility (four items) were adapted from [9,37]. The four items to measure reliability and security were adapted from [45], while cost reduction items were adapted from [9,45]. Each item was measured on a five-point Likert scale. The dependent variable in this study was one self-developed item which asked respondents if their organization had implemented cloud computing for HPC workloads. The second step involved pilot testing. This study was part of a broader international project, CloudLightning [46]. The questionnaire was pilot tested among international academics in the consortium from technical and business disciplines to explore comprehension. Following a number of minor wording changes, the questionnaire was pilot tested among industry members of the project consortium. The third step involved recruiting respondents. Given that HPC is a small knowledge-intensive market, a database was developed to recruit HPC decision makers, which included C-suite employees across various industries from oil and gas to genomics, as well principal investigators at universities. Decision makers were identified through an online search. The survey was distributed to 619 HPC decision-makers worldwide using publicly available email addresses. 
A total of 121 participants completed the survey. This response rate of $19.55 \%$ was deemed adequate given the relatively small number of organizations in the HPC market. Among the sample, $53.30 \%$ are based in the European Union, $36.10 \%$ in North America and the remainder worldwide. Respondents' organizational contexts include academic $(58.20 \%)$, commercial $(27.90 \%)$, and government $(9.80 \%)$. Among these respondents, $45.1 \%$ indicate that they have adopted cloud computing for HPC in their organization, while $54.9 \%$ indicate they have not yet adopted. Respondents reported a range of relevant job titles including CEO, CTO, Professor, Researcher, Scientist, Director, Head of Research and Development to name but a few. This distribution allows us to compare the factors predicting adoption for adopters and non-adopters. As the response rate was slightly lower than the recommended threshold (36+/-13) [47], non-response bias was tested in order to check the representativeness of the responses in this study. Following Wilcox et al. [48], we tested the non-response bias by comparing the organizational variables from the early respondents with the late respondents. The number of HPC users, the weekly HPC usage, and the respondent's familiarity with HPC were used as benchmarking organizational variables. The $t$-test results showed that there was no significant difference between early and late respondents across any of these variables. Therefore, the sample was deemed representative. Exploratory factor analysis was carried out in SPSS 23 to test the reliability and validity of the measures for all key constructs in the new context of HPC. Factor analysis with principal-component factoring method and VARIMAX rotation was used to test discriminant and convergent validity. The Kaiser-Meyer-Olkin (KMO) values of the three dimensions were above the threshold of 0.70 , indicating that these items were suitable for conducting factor analysis. Three factors were generated under the human dimension; personal innovativeness, HPC technical competence, and IT/IS technical competence. Three factors were also generated under the technology dimension; complexity, compatibility, and reliability and security. One item from the security construct was dropped to increase reliability. Four factors were generated under the organization dimension; indirect benefits, adequate resources, top management support, and cost reduction. All Cronbach's alpha values were larger than 0.60 , suggesting that the measures were reliable [49]. All items loaded onto their expected construct with factor loadings above 0.60 . Thus, convergent validity and discriminant validity for each construct were achieved. The composite scores of all factors were calculated for further data analysis. As shown in Table 3, respondents rank innovativeness, compatibility, complexity, indirect benefits, and cost reduction as the most critical factors influencing cloud computing adoption.

Table 3. Descriptive statistics.

\begin{tabular}{llccc}
\hline Dimension & \multicolumn{1}{c}{ Factor } & Mean & Std. Dev. & Rank \\
\hline \multirow{3}{*}{ Human } & Perceived innovativeness & 3.81 & 0.68 & 1 \\
& HPC competence & 3.21 & 1.02 & 6 \\
& IT/IS competence & 2.79 & 0.99 & 10 \\
\hline \multirow{5}{*}{ Organization } & Indirect Benefits & 3.38 & 0.77 & 4 \\
& Adequate resources & 2.88 & 0.9 & 9 \\
& Cost reduction & 3.15 & 0.9 & 7 \\
& Top management support & 2.89 & 0.87 & 8 \\
\hline \multirow{3}{*}{ Technology } & Compatibility & 3.47 & 0.79 & 2 \\
& Reliability and security & 3.25 & 0.81 & 5 \\
& Complexity & 3.45 & 0.8 & 3 \\
\hline
\end{tabular}

To compare the perceptions of adopters and non-adopters, a series of t-tests was conducted. The results presented in Table 4 suggest that adopters and non-adopters have significantly different perceptions of several factors, namely HPC competence, compatibility, indirect benefits, adequacy of resources, top management support, and cost reduction. Unsurprisingly, these mean differences show that adopters perceive cloud computing adoption for HPC more positively than non-adopters. 
Table 4. T-test results of perceptions between adopters and non-adopters.

\begin{tabular}{llrl}
\hline & Adopters & Non-Adopters & T-Value \\
\hline Personal innovativeness & $3.89(0.73)$ & $3.75(0.63)$ & 1.08 \\
HPC competence & $3.48(1.01)$ & $2.98(0.98)$ & $2.71^{* *}$ \\
IT/IS competence & $2.94(0.97)$ & $2.67(1.02)$ & 1.43 \\
Complexity & $3.40(0.87)$ & $3.49(0.73)$ & -0.60 \\
Compatibility & $3.75(0.71)$ & $3.23(0.78)$ & $3.86^{* *}$ \\
Reliability and security & $3.32(0.94)$ & $3.19(0.69)$ & 0.84 \\
Top management support & $3.14(0.85)$ & $2.67(0.83)$ & $3.02^{* *}$ \\
Adequate resources & $3.14(0.99)$ & $2.67(0.77)$ & $2.85^{* *}$ \\
Indirect benefits & $3.71(0.65)$ & $3.10(0.66)$ & $6.13^{* *}$ \\
Cost reduction & $3.40(0.64)$ & $2.94(0.75)$ & $3.66^{* *}$ \\
\hline
\end{tabular}

Note: Numbers in brackets are standard deviations; ${ }^{* *} p<0.01$.

\subsection{Hypothesis Testing}

To test the framework, logistical regression analysis was conducted in SPSS 23 (Table 5). The variance inflation factors (VIF) and tolerance values were calculated to test the multicollinearity of these factors. VIF scores ranged from 1.07 to 2.14, all below the threshold of 3 . The tolerance values ranged from 0.47 to 0.93 , all above the cut-off score of 0.10 . These results suggest that multicollinearity is not an issue [49].

Table 5. Logistic regression results.

\begin{tabular}{lrrrrrr}
\hline & & & & & \multicolumn{3}{c}{ Collinearity } \\
\hline & B & S.E. & Wald & Sig. & Tolerance & VIF \\
\hline Personal innovativeness & 0.04 & 0.36 & 0.01 & 0.91 & 0.93 & 1.07 \\
HPC competence & $0.65^{*}$ & 0.32 & 4.03 & 0.04 & 0.53 & 1.89 \\
IT/IS competence & -0.56 & 0.34 & 2.75 & 0.09 & 0.56 & 1.78 \\
Complexity & -0.24 & 0.32 & 0.56 & 0.45 & 0.86 & 1.16 \\
Compatibility & -0.30 & 0.42 & 0.50 & 0.48 & 0.47 & 2.12 \\
Reliability and security & -0.54 & 0.35 & 2.36 & 0.12 & 0.72 & 1.39 \\
Top management support & 0.49 & 0.37 & 1.75 & 0.18 & 0.47 & 2.14 \\
Adequate resources & 0.40 & 0.37 & 1.16 & 0.28 & 0.48 & 2.09 \\
Indirect benefits & $2.02 * *$ & 0.55 & 13.51 & 0.00 & 0.47 & 2.14 \\
Cost reduction & 0.04 & 0.43 & 0.01 & 0.92 & 0.49 & 2.04 \\
Constant & -6.76 & 2.42 & 7.83 & 0.01 & & \\
\hline
\end{tabular}

Hosmer and Lemeshow: $3.12(p=0.93) ;-2$ log likelihood: 117.23; Cox and Snell R2: 0.325; Nagelkerke pseudo R2: $0.423 .{ }^{* *} p<0.01$; ${ }^{*} p<0.05$.

Model Evaluation. The omnibus test of model coefficients explores whether the independent variables in the model can explain variations in the dependent variable. A significant result suggests that the independent variables can improve the prediction of the dependent variables. In this case, a chi-squared of 44.54, with a degree of freedom of 10 and a significance value below $0.01(p=0.00)$ reveals that the ten factors of interest can significantly improve the prediction of the cloud computing adoption decision.

Goodness-of-fit statistics. The Hosmer and Lemeshow test gives a c2 (8) of 3.12, with a significance value of 0.93 . This non-significant result suggests an acceptable match between the predicted adoption decision and actual adoption decision. $-2 \log$ likelihood ( -2 LL) and Nagelkerke pseudo R-squared were also calculated to show the power of the research model in explaining the data variation. The lower the -2 LL value is, the better the model fit is. In this case, a -2 log likelihood value of 117.23 was acceptable. Nagelkerke Pseudo R-squared represents the amount of variation explained by the model. The model explains $42.3 \%$ of the variance in cloud computing adoption.

Statistical test for individual predictors. Wald chi-square statistics were used to check the predictive ability of individual predictors. The results show that indirect benefits $(p<0.01)$ and HPC 
competence $(p<0.05)$ are statistically significant predictors of cloud computing adoption. Thus, $\mathrm{H} 3$ and $\mathrm{H} 9$ were supported. Indirect benefits and HPC competence are positively related to an organization's likelihood of adopting cloud computing for HPC. Perceptions of IT/IS competence is approaching significance $(p=0.09)$.

Discriminating power. The logistic regression analysis also reveals the predictive accuracy of the research model (Table 6). The model yields a correct prediction rate of $79 \%$ for non-adopters and of $75 \%$ for adopters. The overall correct prediction rate is $77 \%$. These results illustrate that these predictors have sufficiently higher discriminating power than the random choice model.

Table 6. Correct prediction results.

\begin{tabular}{llrrr}
\hline & & Not Adopt & Adopt & \% Correct \\
\hline \multirow{3}{*}{ Baseline } & Not adopt & 62 & 0 & 100 \\
& Adopt & 55 & 0 & 0 \\
& Overall \% & & & 53 \\
\hline \multirow{3}{*}{ Final } & Not adopt & 49 & 13 & 79 \\
& Adopt & 14 & 41 & 75 \\
& Overall \% & & & 77 \\
\hline
\end{tabular}

\section{Critical Issues Impacting HPC in the Cloud}

\subsection{Methodology}

To answer RQ2, a modified Delphi method was conducted to elicit expert opinions on critical issues and problems related to the adoption of HPC in the cloud. It was viewed as an appropriate method due its flexible methodology and suitability to topics where there is limited knowledge as in this study [50]. Delphi inquiries enable researchers to achieve a consensus view from a group of experts on important issues using written responses [51]. An online approach to data collection was used as it reduces the time between iterations [52]. In this study, a four-round online Delphi process was conducted as outlined below in Figure 2. The study consisted of 13 expert participants from five countries including representatives from universities and research centers, SMEs, and multinationals.

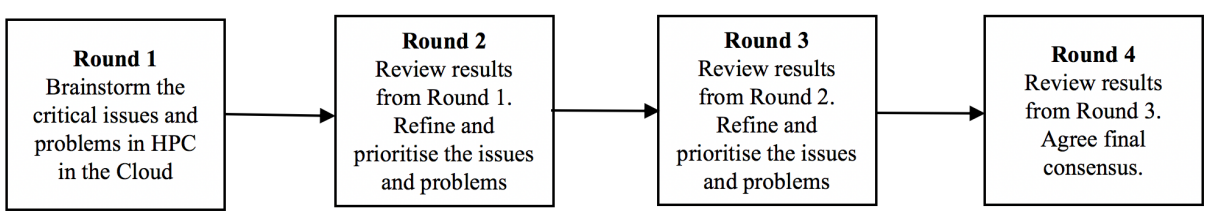

Figure 2. Modified Delphi process.

During each round, experts were asked to provide their comments and carefully examine the comments made by other participants and refine their comments and reprioritize issues until a consensus was reached among the group. In this study, each round of the Delphi had a distinct aim. The aim of round one was to identify all potential issues facing the future of HPC in the cloud. Participants were asked to identify the crucial issues facing HPC in the cloud in the near and further future. These views were collated using an online survey and sent back to participants for them to rank the issues in order of importance. In round two, participants were asked to again review all issues and were reminded of their initial ranking. They were also presented with the results from other experts and asked to reflect on their own opinions and decide whether or not to change the ranks they had assigned. This process continued in rounds three and four until consensus was reached. The data derived from the Delphi process was analyzed in alignment with the research model. 


\subsection{Findings}

Participants identified and achieved consensus on five major critical issues currently impacting the adoption of HPC in the cloud and likely to impact adoption for the next one to five years. The issues are ranked as follows:

1. Data protection concerns [Technological | Organizational]

2. Compliance concerns [Technological | Organizational]

3. Security concerns [Technological]

4. Data control concerns [Technological | Organizational]

5. Privacy concerns [Technological | Organizational]

Participants were worried about the legal constraints and implications of using the cloud, as well as the lack of transparency about data center security in relation to the cloud. In this respect, participants had many of the same concerns as other industry stakeholders and consumers regarding the perceived vulnerabilities of the cloud from a data protection perspective and the implications for them and their organizations, particularly where they were dealing with commercially sensitive or personally sensitive data. Informants highlight that these concerns mostly relate to public cloud use and not private clouds, where the advantages are control and security. However, as also noted by informants, this control and security comes at a cost, in terms of capital and operational expenditure, flexibility, and elasticity. Participants view all of these issues as remaining critical in the longer-term future ( $5+$ years) albeit with a slightly different ranking as outlined below:

1. Privacy concerns [Technological | Organizational]

2. Security concerns [Technological]

3. Data protection concerns [Technological | Organizational]

4. Data control concerns [Technological । Organizational]

5. Compliance concerns [Technological | Organizational]

The long-term ranking suggests that security will remain a critical issue, but external privacy concerns will be much more important than general internal data protection and control concerns. This suggests a shift in focus from internal issues or pressures to external ones. Notwithstanding these main findings from the Delphi study, it should be noted that informants discussed many issues which transcend human, organizational, and technological categories, namely the issue of performance or perceptions around performance. In this way, this second study makes a significant contribution in that it unpacks the compatibility dimension from Study 1 to identify some latent concerns regarding the capabilities of cloud infrastructure to achieve the same levels of performance as conventional HPC. Several informants highlighted performance as a core issue for the next five years and longer term but albeit from different perspectives. Proponents of HPC noted concerns around the technology itself including perceptions of workload compatibility and communications speeds to match the demands of HPC. In addition, they noted organizational concerns including funding and resources. In contrast, cloud proponents suggested that, human factors, including potentially flawed perceptions of cloud computing might hinder individuals' willingness to consider, let alone, adopt cloud computing in this context. Notwithstanding this, the technological impact of performance did not rank as high due to agreement that in many cases cloud computing may be appropriate e.g., loosely coupled workloads such as 3D image rendering, MATLAB programs, or simulations, and in others not so appropriate, e.g., workloads requiring high interprocessor communication speeds. Similarly, while not ranking as a major concern, education and training and the need for higher education to provide a pipeline of both HPC and cloud computing graduates were noted by all.

\section{Discussion}

Integrating DOI and HOT-fit, our quantitative findings suggests that organizational and human factors significantly influence organizations' cloud computing adoption decisions for HPC. Specifically, 
decision makers' perceptions of indirect benefits and existing HPC competences predict their cloud computing adoption decisions with an overall correct prediction rate of $77 \%$. Notwithstanding this, our qualitative findings suggest that organizational and technological issues related to data privacy and security are a significant concern today and will be in to the future.

Human factors. The results indicate that, even though innovativeness is high, this does not necessarily lead to cloud computing adoption. This finding is inconsistent with previous studies [5,9]. Descriptive statistics reported in Table 3 show that personal innovativeness is the top-rated factor of cloud computing adoption for HPC. Thus, the reasons behind this inconsistency merit further investigation. The results also suggest that organizations with superior HPC competences perceive themselves to possess more advanced computing abilities, and thus are more willing to adopt cloud computing [8]. The insignificant relationship between IT competences and adoption may be because organizations with sufficient IT expertise may have gone through some of the technological changes required for cloud computing, reducing the impact of technological competences on the cloud computing adoption but an increased effect on the extent of cloud computing implementation [6]. Existing literature also reports mixed results with some reporting positive impacts $[8,29,32]$, while others report insignificant results $[6,34]$. Human factors thus require further investigation.

Technological factors. None of the technological factors-compatibility, complexity, and reliability and security-influence the adoption of cloud computing for HPC. However, there may be alternative explanations for these results. First, organizations may realize that the benefits of adopting cloud computing for HPC are likely to outweigh the perceived complexity. Thus, they may adopt cloud computing for HPC to maximize these perceived benefits. Second, the results may reflect different cloud conceptualizations. Pure private clouds, and hybrid clouds may not have the same security concerns as public clouds although this is widely disputed (see, for example, [39]). Third, if the organizations perceive themselves as having superior existing technological competences, they may adopt cloud computing regardless of the compatibility between cloud computing and their existing HPC systems or processes. Fourth, though cloud security remains a major concern [5], the technological advances in securing data privacy and confidentiality on cloud computing platforms may have given organizations confidence in implementing cloud services [7,39]. Furthermore, as highlighted by the Delphi study, data privacy and security are both a significant concern for HPC in the cloud today and moving forward, which needs to be addressed by the cloud computing industry.

Organizational factors. Only perceived indirect benefits significantly influenced cloud computing adoption decision for HPC. This is congruent with previous studies [3,8,29], suggesting that indirect benefits have a strong influence on adoption [33]. A useful implication arising from this is that cloud computing service providers should highlight the wider set of benefits associated with adopting cloud computing for HPC to their customers in order to increase their likelihood to adopt. Surprisingly, adequate resources and top management support are not found to influence cloud computing adoption for HPC. These results contradict many prior studies [5-7,29]. Finally, cost reduction does not influence cloud computing adoption for HPC. This may be HPC-specific as HPC typically involves specialist computing and scientific expertise where the decision-making is devolved to those with the required expertise. Similarly, HPC has a high cost profile compared to general IT expenditure. This may also reflect a sampling characteristic. The sample comprises organizations operating in the traditional HPC market not SMEs. The use of cloud computing for cost efficiencies is a widely reported benefit for smaller or new enterprises [32]. However, as larger organizations have sufficient resources they are less likely to adopt cloud computing for the purpose of cost reduction.

\section{Conclusions}

The realization of the benefits of HPC has been somewhat limited due partly to the large start-up costs required. This paper leverages HOT-fit and DOI (i) to identify the determinants of cloud computing adoption for HPC, and (ii) elicit expert opinions on the issues facing HPC in the cloud in the near and long-term future. The paper makes two important contributions. First, the study 
incorporates DOI with HOT-fit theories to provide a holistic view of determinants of cloud computing adoption for HPC. As indicated earlier, there is a dearth of research on cloud computing adoption in the HPC area. Thus, this study provides important insights and answers calls for clarification on the drivers and inhibitors of cloud computing adoption in differing contexts [31]. Second, this paper contributes both to literature and practice by providing insights for cloud service providers with findings suggesting that cloud service providers should emphasize the indirect benefits of adopting cloud computing for HPC in their communications to potential customers and specifically address issues and concerns relating to data privacy and security. However, as is the case with all studies, this paper is not without its limitations. These include the use of single-informant, the small sample size, and potential over-representation in the sample from the academic community. The results would be more robust with data from multiple respondents and from a larger sample. When considering the diversity of the sample, a comparison of attitudes towards different cloud deployment models (public, private, hybrid, federated, and community) and service models (IAAS, PAAS, SAAS) may prove insightful. Furthermore, future research could explore the role of these factors over time to see which factors are more influential in the short and long term. It is our hope that this research can inform future research which seeks to explore the adoption and assimilation of new technologies in complex contexts.

Author Contributions: Conceptualization, T.L., G.F., and A.G.; methodology, T.L. and G.F.; data collection, T.L. and A.G.; analysis, T.L., A.G., G.F., and P.R.; resources, T.L. and P.R.; discussion, T.L., A.G., G.F., and P.R.; writing —original draft preparation, T.L., A.G., G.F., and P.R.; writing—review and editing, T.L., A.G., G.F., and P.R. All authors have read and agreed to the published version of the manuscript.

Funding: This work is partially funded by the European Union's Horizon 2020 Research and Innovation Programme through the CloudLightning project (http://www.cloudlightning.eu) under Grant Agreement Number 643946,the Irish Institute of Digital Business, and by the Irish Centre for Cloud Computing and Commerce (IC4), an Enterprise Ireland/IDA technology centre.

Conflicts of Interest: The authors declare no conflict of interest.

\section{Abbreviations}

The following abbreviations are used in this manuscript:

$\begin{array}{ll}\text { AI } & \text { Artificial Intelligence } \\ \text { BDA } & \text { Big Data Analytics } \\ \text { CEO } & \text { Chief Executive Officer } \\ \text { CTO } & \text { Chief Technology Officer } \\ \text { DOI } & \text { Diffusion of Innovation } \\ \text { HOT-fit } & \text { Human, Organizational, and Technological fit } \\ \text { HPC } & \text { High Performance Computing } \\ \text { IAAS } & \text { Infrastructure As A Service } \\ \text { IC4 } & \text { Irish Center for Cloud Computing and Commerce } \\ \text { ICT } & \text { Information and Communications Technology } \\ \text { IDC } & \text { International Data Corporation } \\ \text { IS } & \text { Information Systems } \\ \text { IT } & \text { Information Technology } \\ \text { PAAS } & \text { Platform As A Service } \\ \text { SAAS } & \text { Software As A Service } \\ \text { TAM } & \text { Technology Acceptance Model } \\ \text { TOE } & \text { Technological, Organizational, and Environmental } \\ \text { TRA } & \text { Theory of Reasoned Action } \\ \text { UTAUT } & \text { Unified Theory of Technology Acceptance and Usage }\end{array}$




\section{References}

1. Oliinyk, I.; Echikson, W. Europeś Payments Revolution. Stimulating Payments Innovation While Protecting Consumer Privacy. http:/ / aei.pitt.edu/94533/ (accessed on 11 August 2020).

2. Maqueira-Marín, J.M.; Bruque-Cámara, S.; Minguela-Rata, B. Environment determinants in business adoption of Cloud Computing. Ind. Manag. Data Syst. 2017, 117, 228-246. [CrossRef]

3. Phaphoom, N.; Wang, X.; Samuel, S.; Helmer, S.; Abrahamsson, P. A survey study on major technical barriers affecting the decision to adopt cloud services. J. Syst. Softw. 2015, 103, 167-181. [CrossRef]

4. Cegielski, C.G.; Jones-Farmer, A.; Wu, Y.; Hazen, B.T. Adoption of cloud computing technologies in supply chains. Int. J. Logist. Manag. 2012, 23, 184-211. [CrossRef]

5. Alshamaila, Y.; Papagiannidis, S.; Li, F. Cloud computing adoption by SMEs in the north east of England: A multi-perspective framework. J. Enterp. Inf. Manag. 2013, 26, 250-275. [CrossRef]

6. Low, C.; Chen, Y.; Wu, M. Understanding the determinants of cloud computing adoption. Ind. Manag. Data Syst. 2011, 111, 1006-1023. [CrossRef]

7. Oliveira, T.; Thomas, M.; Espadanal, M. Assessing the determinants of cloud computing adoption: An analysis of the manufacturing and services sectors. Inf. Manag. 2014, 51, 497-510. [CrossRef]

8. Hsu, P.F.; Ray, S.; Li-Hsieh, Y.Y. Examining cloud computing adoption intention, pricing mechanism, deployment model. Int. J. Inf. Manag. 2014, 34, 474-488. [CrossRef]

9. Lian, J.W.; Yen, D.C.; Wang, Y.T. An exploratory study to understand the critical factors affecting the decision to adopt cloud computing in Taiwan hospital. Int. J. Inf. Manag. 2014, 34, 28-36. [CrossRef]

10. Geist, A.; Reed, D.A. A survey of high-performance computing scaling challenges. Int. J. High Perform. Comput. Appl. 2017, 31, 104-113. [CrossRef]

11. Zenios, S.A. High-performance computing in finance: The last 10 years and the next. Parallel Comput. 1999, 25, 2149-2175. [CrossRef]

12. IDC. Worldwide Broader HPC 2014-2018 Forecast: Servers, Storage, Software, Middleware, and Services; IDC: Framingham, MA, USA, 2015.

13. Hyperion Research. HPC Market Update; Hyperion Research: Saint Paul, MN, USA, 2018.

14. Gupta, A.; Milojicic, D. Evaluation of hpc applications on cloud. In Proceedings of the 2011 Sixth Open Cirrus Summit, Atlanta, GA, USA, 12-13 October 2011; IEEE: Piscataway, NJ, USA, 2011; pp. 22-26.

15. Mauch, V.; Kunze, M.; Hillenbrand, M. High performance cloud computing. Future Gener. Comput. Syst. 2013, 29, 1408-1416. [CrossRef]

16. Aldinucci, M.; Rabellino, S.; Pironti, M.; Spiga, F.; Viviani, P.; Drocco, M.; Guerzoni, M.; Boella, G.; Mellia, M.; Margara, P.; et al. HPC4AI: An AI-on-demand federated platform endeavour. In Proceedings of the 15th ACM International Conference on Computing Frontiers, Ischia, Italy, 8-10 May 2018; pp. 279-286.

17. Lynn, T. Addressing the complexity of HPC in the cloud: Emergence, self-organisation, self-management, and the separation of concerns. In Heterogeneity, High Performance Computing, Self-Organization and the Cloud; Palgrave Macmillan: London, UK, 2018; pp. 1-30.

18. Beck, R.; Tönker, M. Increasing Dynamic Capabilities through Virtualized Grid-in-Cloud Solutions. In Proceedings of the 33rd International Conference on Information Systems (ICIS 2012), Orlando, FL, USA, 16-19 December 2012.

19. Thackston, R.; Fortenberry, R. High performance computing: Considerations when deciding to rent or buy. In Proceedings of the SAIS 2015 Proceedings, Hilton Head Island, SC, USA, 20-21 March 2015.

20. Evangelinos, C.; Hill, C. Cloud computing for parallel scientific hpc applications: Feasibility of running coupled atmosphere-ocean climate models on amazons ec2. Ratio 2008, 2, 2-34.

21. Venkatesh, V.; Morris, M.G.; Davis, G.B.; Davis, F.D. User acceptance of information technology: Toward a unified view. Manag. Inf. Syst. Q. 2003, 27, 425-478. [CrossRef]

22. Lynn, T.; Liang, X.; Gourinovitch, A.; Morrison, J.P.; Fox, G.; Rosati, P. Understanding the determinants of cloud computing a.option for high performance computing. In Proceedings of the 51st Hawaii International Conference on System Sciences (HICSS-51), University of Hawai'i at Manoa, Waikoloa Village, HI, USA, 2-6 January 2018; pp. 3894-3903.

23. Rogers, E.M. Diffusion of Innovations; Simon and Schuster: New York, NY, USA, 2003.

24. Fishbein, M.; Ajzen, I. Belief, Attitude, Intention, and Behavior: An Introduction to Theory and Research; Addison Wesley Publishing Company: Boston, MA,USA, 1977. 
25. Davis, F.D. Perceived usefulness, perceived ease of use, and user acceptance of information technology. Manag. Inf. Syst. Q. 1989, 13, 319-340. [CrossRef]

26. Davis, F.D.; Bagozzi, R.P.; Warshaw, P.R. User acceptance of computer technology: A comparison of two theoretical models. Manag. Sci. 1989, 35, 982-1003. [CrossRef]

27. Tornatzky, L.; Fleischer, M. The Process of Technology Innovation; Lexingt. Books: Lexington, MA, USA, 1990; Volume 165.

28. Rogers, E. Diffusion of Innovations, 4th ed.; The Free Press: Detroit, MI, USA, 1995; pp. 15-23.

29. Gangwar, H.; Date, H.; Raoot, A. Review on IT adoption: Insights from recent technologies. J. Enterp. Inf. Manag. 2014, 27, 488-502. [CrossRef]

30. Yusof, M.M.; Papazafeiropoulou, A.; Paul, R.J.; Stergioulas, L.K. Investigating evaluation frameworks for health information systems. Int. J. Med. Inform. 2008, 77, 377-385. [CrossRef]

31. Asatiani, A. Why cloud? Aa review of cloud adoption determinants in organizations. In Proceedings of the European Conferences on Information Systems 2015 (ECIS 2015), Münster, Germany, 26-29 May 2015.

32. Lin, A.; Chen, N.C. Cloud computing as an innovation: Percepetion, attitude, and adoption. Int. J. Inf. Manag. 2012, 32, 533-540. [CrossRef]

33. Gupta, P.; Seetharaman, A.; Raj, J.R. The usage and adoption of cloud computing by small and medium businesses. Int. J. Inf. Manag. 2013, 33, 861-874. [CrossRef]

34. Wu, Y.; Cegielski, C.G.; Hazen, B.T.; Hall, D.J. Cloud computing in support of supply chain information system infrastructure: Understanding when to go to the cloud. J. Supply Chain Manag. 2013, 49, $25-41$. [CrossRef]

35. Hazen, B.T.; Wu, Y.; Sankar, C.S.; Jones-Farmer, L.A. A proposed framework for educational innovation dissemination. J. Educ. Technol. Syst. 2012, 40, 301-321. [CrossRef]

36. Agarwal, R.; Prasad, J. A conceptual and operational definition of personal innovativeness in the domain of information technology. Inf. Syst. Res. 1998, 9, 204-215. [CrossRef]

37. Premkumar, G.; Roberts, M. Adoption of new information technologies in rural small businesses. Omega 1999, 27, 467-484. [CrossRef]

38. Joseph, E.; Sorensen, B.; Norton, A.; Conway, S. Research Highlights In HPC, HPDA-AI, Cloud Computing, Quantum Computing, The Global Exascale Race, and Innovation Award Winners; Hyperion Research: Saint Paul, MN, USA, 2018.

39. Amazon Web Services, Intel. Challenging the Barriers to High Performance Computing in the Cloud; Amazon Web Services: Seattle, WA, USA, 2019.

40. Lee, S.; Kim, K.j. Factors affecting the implementation success of Internet-based information systems. Comput. Hum. Behav. 2007, 23, 1853-1880. [CrossRef]

41. Hayes, B. Cloud computing. Commun. ACM 2008, 51, 9-11. [CrossRef]

42. Chang, I.C.; Hwang, H.G.; Hung, M.C.; Lin, M.H.; Yen, D.C. Factors affecting the adoption of electronic signature: Executives' perspective of hospital information department. Decis. Support Syst. 2007, 44, 350-359. [CrossRef]

43. Kuan, K.K.; Chau, P.Y. A perception-based model for EDI adoption in small businesses using a technology-organization-environment framework. Inf. Manag. 2001, 38, 507-521. [CrossRef]

44. Marston, S.; Li, Z.; Bandyopadhyay, S.; Zhang, J.; Ghalsasi, A. Cloud computing-The business perspective. Decis. Support Syst. 2011, 51, 176-189. [CrossRef]

45. Soliman, K.S.; Janz, B.D. An exploratory study to identify the critical factors affecting the decision to establish Internet-based interorganizational information systems. Inf. Manag. 2004, 41, 697-706. [CrossRef]

46. Lynn, T.; Xiong, H.; Dong, D.; Momani, B.; Gravvanis, G.A.; Filelis-Papadopoulos, C.K.; Elster, A.C.; Khan, M.M.Z.M.; Tzovaras, D.; Giannoutakis, K.M.; et al. CLOUDLIGHTNING: A Framework for a Self-organising and Self-managing Heterogeneous Cloud. In Proceedings of the 6th International Conference on Cloud Computing and Services Science (CLOSER 2016), Rome, Italy, 23-25 April 2016; pp. 333-338.

47. Baruch, Y. Response rate in academic studies-A comparative analysis. Hum. Relat. 1999, 52, 421-438. [CrossRef]

48. Wilcox, J.B.; Bellenger, D.N.; Rigdon, E.E. Assessing sample representativeness in industrial surveys. J. Bus. Ind. Market. 1994, 9, 51-61. [CrossRef]

49. Hair, J.F.; Anderson, R.E.; Babin, B.J.; Black, W.C. Multivariate Data Analysis: A Global Perspective, 7th ed.; Pearson: Upper Saddle River, NJ, USA, 2010. 
50. Skulmoski, G.J.; Hartman, F.T.; Krahn, J. The Delphi method for graduate research. J. Inf. Technol. Educ. Res. 2007, 6, 1-21. [CrossRef]

51. Delbecq, A.L.; Van de Ven, A.H.; Gustafson, D.H. Group Techniques for Program Planning: A Guide to Nominal Group and Delphi Processes; Scott, Foresman: Northbrook, IL, USA, 1975.

52. Steinert, M. A dissensus based online Delphi approach: An explorative research tool. Technol. Forecast. Soc. Chang. 2009, 76, 291-300. [CrossRef]

(C) 2020 by the authors. Licensee MDPI, Basel, Switzerland. This article is an open access article distributed under the terms and conditions of the Creative Commons Attribution (CC BY) license (http:/ / creativecommons.org/licenses/by/4.0/). 